\title{
CONTINUING EDUCATION IN RHEUMATOID ARTHRITIS FOR THE PRIMARY CARE PHYSICIAN
}

\author{
JEOFFREY K. STROSS and GILES G. BOLE
}

An educational program in rheumatoid arthritis was developed for primary care practitioners. This program is community based and utilizes physicians, identified by their peers as being influential, for the dissemination of information. A marked change in knowledge has been noted in those completing the program, but further followup is needed to determine if a change in the care of patients with rheumatoid arthritis will also result.

The National Commission on Arthritis in its report to the United States Congress in April 1976 noted that rheumatologists treat only $3 \%$ of the patients afflicted with rheumatic disease. This estimate was based upon a professional manpower survey conducted under the auspices of the Arthritis Foundation in 1973. The survey also found that of the primary care physicians who treat most of the patients with rheumatic disorders, $70 \%$ had received little or no formal education in the management of these diseases. Surveys by the Professional Education Committee of the Arthritis Foundation have indicated that over two-thirds of the medical schools report inadequate numbers of rheumatologists in their institutions or available in the medical community to conduct professional educational programs (1). Thus, new approaches to education of the physician

From the University of Michigan Arthritis Center and the Department of Internal Medicine, University of Michigan Medical School.

Supported by the Multipurpose Arthritis Centers Grant 1 P60 AM 20557-01, National Institute of Arthritis, Metabolism, and Digestive Diseases.

Jeoffrey K. Stross, MD; Giles G. Bole, MD.

Address reprint requests to Dr. Stross, Towsley Center for CME, Ann Arbor, Michigan 48109.

Submitted for publication January 22, 1979; accepted February $21,1979$. groups responsible for care and treatment of the vast majority of patients with arthritis are needed now.

The need for continuing medical education (CME) for physicians is well recognized and encompasses all the fields of clinical practice. Many states are either moving toward or have already adopted legislation mandating participation in CME as a prerequisite for relicensure. Participation in CME is perceived as a means of maintaining competency by imparting new knowled'ge and skills, correcting educational deficiencies, providing reassurance, and stimulating intellectual curiosity.

There is a great deal of variation in the types of continuing medical education offered today with short courses sponsored by academic medical centers, medical societies, and national organizations being the most popular and widely attended (2). These traditional approaches to continuing education have their shortcomings, however, and the most common complaints are that they are irrelevant to the practice setting of the individual physician, unstimulating because of passive learning methods, and inconvenient in that they require the physician to travel to another community and be absent from practice. Although journals and books are available in abundance, they generally require a large amount of reading for a small amount of relevant information.

Primary care physicians practicing in a community setting must rely to a great extent upon more informal and personal methods of education. Actual experiences acquired in the process of diagnosing and treating illness are probably the strongest influences that bring about changes in professional practices. Because of the rapid increase in knowledge concerning the rheumatic 
diseases, there is a definite demand for continuing education in this field. As part of the community outreach activities of the University of Michigan Arthritis Center, we initiated an education program for primary care physicians in the management of adult onset rheumatoid arthritis (RA). The program focused upon the most common form of inflammatory joint disease. This program utilized adult learning methodologies and is consistent with the principles recently described at the 1977 World Rheumatism Year Workshop (3).

In this article the instructional objectives, needs assessment, program design, educational format, and evaluation of preliminary data are presented. The initial findings emphasize the importance of community-based CME and describe a new approach to education of the primary care physician which will be subjected to ongoing assessment and evaluation. It is hoped that this presentation will stimulate others to design new programs that meet the needs of the primary care physician.

\section{THE PROGRAM}

\section{Instructional objectives}

The first step in this program was the development of clearly defined educational objectives. A group of primary care physicians as well as a group of rheumatologists met independently to determine what knowledge and skills the primary care physician should have to adequately care for patients with RA. There were four major categories identified: recognition of the clinical signs and symptoms, management, referral, and education of patients with RA. For each one of these categories, instructional objectives relating to knowledge and skills were identified and these are outlined in Table 1 .

Differences between the groups were minor and resolved by mutual agreement. The major area of concern to the primary care practitioners focuses upon the management of patients with RA. These objectives state that the primary care practitioner should be able to give maintenance gold and corticosteroid therapy. This physician should also be able to administer intraarticular corticosteroid therapy when indicated. What is not directly stated, but obviously implied, is that the primary care practitioner should not initiate either gold or systemic corticosteroid therapy without first seeking advice from a consultant. These recommendations caused concern for the primary care practitioner because they set limits on what a physician should do, irrespective of whether what was being suggested was the correct ap- proach. The other area discussed related to who should be referred to other facilities for rheumatology consultation, physical therapy, or reconstructive surgery. The practical problems of not knowing the availability of services or personnel were discussed and the need for an inventory of rheumatology services was stressed. Aside from these areas, there was agreement among both groups as to the appropriateness of these instructional objectives.

\section{Needs assessment}

After defining the educational objectives, it was necessary to assess the knowledge and skill level of primary care physicians to determine if they already possessed the desired level of knowledge and skills. This was done in two ways: objective testing and retrospective chart audit.

Primary care physicians from six communities in the state were asked to participate in this phase of the project. These communities had the following characteristics: a population less than 15,000 , at least 10 primary care physicians, a less than 200 bed hospital, no rheumatologist in the physician population, and a location more than 25 miles from a city with a rheumatologist. Primary care physicians in these communities were given a written examination to complete and $75 \%$ of those contacted returned the completed examination. The questions were derived from each of the instructional objectives, and were true/false, multiple choice, or matching. In addition, all charts from patients hospitalized in the previous year with a discharge diagnosis of RA were audited to document the historical, physical, and diagnostic findings as well as the treatment provided. A similar audit was also conducted in outpatient settings.

The objective testing revealed that the physicians answered $63 \%$ ( 38 of 60 ) of the questions correctly. The major deficiencies in knowledge related to the identification of the radiographic features of the disease, the use and interpretation of serologic studies, and the drug management of RA.

Rheumatoid arthritis was the primary discharge diagnosis in 52 instances in the six community hospitals studied. Among discharge diagnoses it ranks 124th according to Commission on Professional Hospital Activity data, accounting for almost 29,000 discharges in 1976. This diagnostic category also accounts for 25 of every 10,000 discharges, so that the number of cases identified is consistent with what would be predicted from the six hospitals' total discharge number of 22,000 (4). 
Table 1. Instructional objectives in rheumatoid arthritis for primary care practitioners

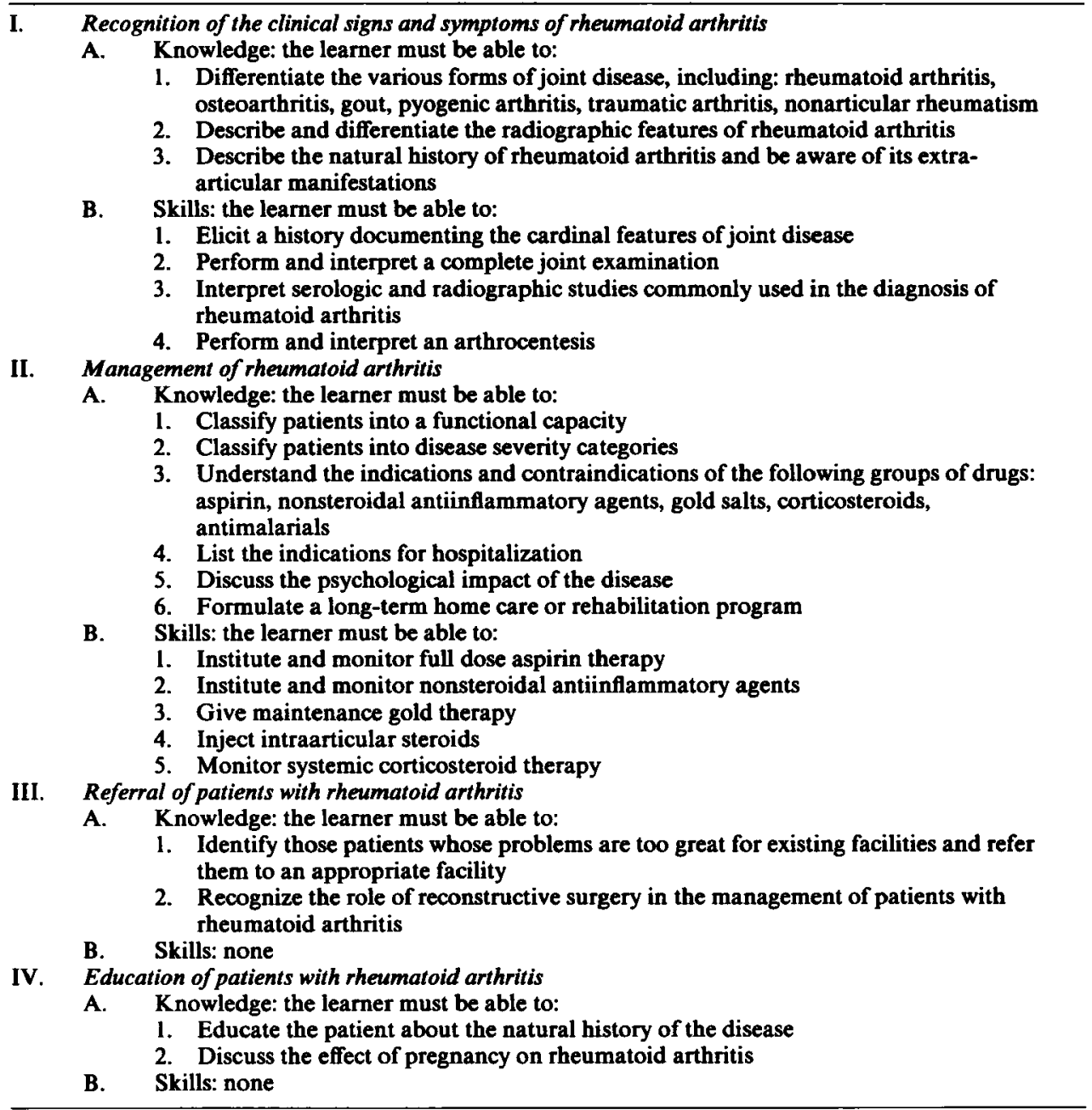

The results of the inpatient audit are outlined in Table 2. The historical findings were poorly documented with little attention given to the complications of therapy. Although a physical examination was recorded for each patient, there was little documentation of joint findings. Diagnostic studies were infrequently obtained, possibly because they had been done previously in the physician's office. On the basis of the meager information present in the record it was not possible to determine if diagnostic criteria were met or to assess the patients' functional capacity or stage of disease. Treatment was also inconsistent from patient to patient. There was little evidence that a coordinated treatment plan had been developed regarding the use of medications and physical therapy.

Whereas only 52 patient discharges were recorded for the six hospitals during the one year study period, 98 patients were identified in the audit of the outpatient charts of 24 physicians. Each primary care physician in the six communities was asked to keep a log of all patients with RA whom they saw during a 2month period as well as any other patients with RA in their practice. Seventy percent of the available physicians complied and 98 patients were identified. This method clearly underestimates the total number of patients with RA in these communities since it identified only patients from $70 \%$ of the primary care practitioners, thus omitting patients being cared for by others. In addition, it primarily identified patients seen during that 2 -month period since only $20 \%$ of the patients identified were not seen during the study period. Since patients were seen only about three times a year (Table 3), we estimate that approximately $50 \%$ of patients with RA were identified. This suggests a prevalence rate of $0.4 \%$ 
Table 2. RA inpatient audit results*

\begin{tabular}{lc}
\multicolumn{1}{c}{ Audit criteria } & $\begin{array}{c}\text { Number documented } \dagger \\
(\%)\end{array}$ \\
\hline History & $1(2)$ \\
Symptoms of inflammation & $4(8)$ \\
Extraarticular manifestations & $25(48)$ \\
Medications & $5(10)$ \\
Complications of therapy & \\
Physical exam & $13(25)$ \\
Heat, redness, swelling & $26(50)$ \\
Range of motion & $20(39)$ \\
Deformity & \\
Diagnostic studies & $32(62)$ \\
Sedimentation rate & $6(12)$ \\
Latex fixation & $8(15)$ \\
Joint x-rays & \\
Management & $32(62)$ \\
Aspirin & $12(23)$ \\
Nonsteroidal antiinflammatory agents & $12(23)$ \\
Gold & $21(40)$ \\
Corticosteroids & $33(64)$ \\
Physical therapy &
\end{tabular}

$* N=52$.

† The number of charts where a statement was made about the presence or absence of a finding.

(200 cases/50,000 population), substantially below that reported by some (5), and similar to that reported by others (6-7).

The audit in the outpatient setting also demonstrated poor documentation of the history and physical findings so that the accuracy of the diagnosis, the functional capacity, and the disease severity could not be assessed. The medications most commonly used are noted in Table 3. While aspirin was used in $56 \%$ of cases, corticosteroids were used in $\mathbf{4 0 \%}$ as were the nonsteroidal antiinflammatory agents. There was evidence that physical therapy was either used or prescribed in only $13 \%$ of cases.

\section{Educational materials}

Educational materials were designed according to the following criteria: that they contain accurate in-

Table 3. RA outpatient audit results*

\begin{tabular}{lc}
\hline \multicolumn{1}{c}{ Audit criteria } & Number (\%) \\
\hline Males & $33(34)$ \\
Females & $65(66)$ \\
Average number of visits/year & $2.83 \dagger$ \\
Treatment program & \\
$\quad$ Aspirin & $55(56)$ \\
Gold & $22(22)$ \\
Nonsteroidal antiinflammatory agents & $37(38)$ \\
Corticosteroids & $39(40)$ \\
Physical therapy & $13(13)$ \\
\hline
\end{tabular}

$* \mathrm{~N}=98$.

† Visits for gold injections only are not included. formation derived from authoritative sources, be based upon clearly defined educational objectives, be of high quality, be appropriate for the identified needs of the learner group, be presented in a modality that is intrinsically motivating, and allow for active learner involvement. In addition, the program must be produced at a reasonable cost with minimal duplication expenses. The materials selected included textbooks, a syllabus of recent articles, and audiovisual programs, all of which could be used for individual or small group use.*

Prior to selecting these materials, a survey of the medical libraries in these communities was conducted. Because there were no textbooks or journals that dealt with rheumatic diseases, it was decided to provide textbooks not only for their broad scope of information, but as reference materials for future use. Journal articles covering the instructional objectives were also collected, reviewed, and catalogued into a syllabus. This then provided a concise review of the recent literature dealing with the diagnosis, treatment, and education of patients with RA. Audiovisual materials were identified by an AVLINE search and reviewed for use. We selected those materials which demonstrated subject matters that could best be shown using motion and sound. Slide/ tape programs demonstrating how to perform and interpret arthrocenteses were particularly useful.

In addition to these materials, a preceptorship within the University of Michigan Arthritis Center has been initiated. This enables physicians to come into the academic medical center and gain experience under supervision that may not be available within the community. The trainees participate in both inpatient and outpatient teaching activities, attend conferences, and develop some expertise in performing and interpreting arthrocenteses, for example. This also provides us with an opportunity of determining the knowledge and skill level of the trainee. Whereas testing for knowledge can be satisfactorily accomplished in various ways, skill levels can best be assessed by direct observation.

\section{Educational format}

Although this program could be utilized by any physician with an interest in RA, it was aimed at a specific group of primary care practitioners who were identified by their peers as being influential practitioners. They are the individuals who other physicians turn to for knowledge and they play an important role in the dissemination of new information. These physicians have been found to function very effectively as formal

* A compilation of materials used is available upon request. 
and informal consultants to their colleagues. They are generally board certified, frequently internists or surgeons who spend more time at the hospital, serve on more hospital committees, and depend more on written than oral communication in their work. They have positive attitudes toward teaching others and favor a general strengthening of local problem-solving abilities.

These individuals were identified by first interviewing community hospital physicians and asking them to identify those behaviors demonstrated by physicians they turned to most often for advice and consultation. Seventy-eight characteristics were listed and categorized into four basic areas: communication, function, performance, and personal attributes. Twentysix descriptors were developed from these characteristics and assembled into a survey instrument. This was administered to over 300 physicians and they rated the extent to which each of the descriptors described these influential practitioners. Factor analysis of the results demonstrated that three attributes were important: communication, humanism, and knowledge. Based upon these results, a final survey instrument was developed. This instrument consisted of three paragraphs, each one accurately describing one of the three major factors. Physicians were then asked to nominate up to three individuals whom they felt best fit the description, and the nominations were totaled and rank ordered. The instrument has been used in 16 communities and has yielded a single individual in all but one, where two individuals received the same (8).

Recruitment of these individuals into a project has not been a problem; twelve individuals have been contacted and asked to participate in a variety of educational projects and no one has declined to date.

\section{Evaluation}

Physicians who completed the self-study program have demonstrated a marked increase in performance on the tests of knowledge. The average correct score of $64 \%$ on the pre-test improved to $86 \%$ on the post-test. Further chart reviews in both inpatient and outpatient settings will be undertaken in the future to determine if this change in knowledge will be translated into a change in behavior in the care of patients with RA, not only for the influential physicians but for their colleagues as well.

Most of the changes we will be looking for will be related to the process of delivering care, since the outcomes of death, discomfort, disability, drug morbidity, and cost are difficult to measure, and as we have noted, the medical record is a relatively poor indicator of what actually occurred.

\section{SUMMARY}

Since RA is a relatively common disease and only $3 \%$ of patients are cared for by physicians with special training in rheumatology, we thought it would be worthwhile to establish instructional objectives for the 97\% of physicians who care for most patients with RA. Although these objectives may be controversial, the needs assessment including the inpatient and outpatient audit clearly document the variance between present activity and our stated objectives.

It is obvious that traditional forms of continuing medical education have not been successful in improving the care of patients with RA. If this present approach, based upon disseminating information utilizing educationally influential physicians, is successful, it should have a major impact on how continuing education should be carried out in the future. Even if it proves to be of limited value, the instructional objectives and the needs assessment should be useful to all providers of continuing education. It is hoped that this presentation will stimulate broad interest in the development, implementation, and evaluation of new approaches to education of primary care physicians in the field of rheumatic disease.

\section{REFERENCES}

1. National Commission on Arthritis and Related Musculoskeletal Diseases: Report to the Congress of the United States. April, 1976

2. Stross JK, Harlan WR: The impact of mandatory continuing medical education. JAMA 239:2663-2666, 1978

3. Rudd $E$, Lockshin MD: Education in rheumatology for the primary care physician. J Rheumatol 5:99-111, 1978

4. Commission on Professional and Hospital Activities: Length of stay in PAS hospitals, by diagnosis, United States, 1976. Ann Arbor, 1977, pp 213, 233

5. Cathcart ES, O'Sullivan JB: Rheumatoid arthritis in a New England town: a prevalence study in Sudbury, Massachusetts. N Engl J Med 282:421-424, 1970

6. Bennett PH, Burch TA: New York symposium on population studies in the rheumatic diseases: new diagnostic criteria. Bull Rheum Dis 17:453-458, 1967

7. Mikkelsen WM, Dodge HJ, Duff IF, Kato H: Estimates of the prevalence of rheumatic diseases in the population of Tecumseh, Michigan 1959-1960. J Chron Dis 20:351-369, 1967

8. Hiss RG, Macdonald R, Davis WK: Identification of physician educational influentials in small community hospitals. Proceedings Seventeenth Annual Conference on Research in Medical Education, 283-288, 1978 